\title{
Biology and Morphometry of Corcyra cephalonica Stain in Sesamum Seeds during Storage
}

\author{
Soumya B. Babu ${ }^{1 *}$, T. Samal ${ }^{1}$, M. K. Mishra ${ }^{2}$, S. Mohanty ${ }^{3}$ and Jubuli Sahu ${ }^{4}$ \\ ${ }^{1}$ Department of Entomology, ${ }^{2}$ Department of Plant Pathology, College of Agriculture, \\ OUAT, Bhubaneswar, Odisha, India \\ ${ }^{3}$ Seed Technology Research AICRP-NSP (Crops) O.U.A.T., Bhubaneswar, India \\ ${ }^{4} \mathrm{SMS}$ (Agromet), KVK, Banka, Bihar, India \\ *Corresponding author
}

\section{A B S T R A C T}

\begin{tabular}{l} 
Ke y w o r d s \\
$\begin{array}{l}\text { Corcyra } \\
\text { cephalonica Stain, } \\
\text { Biology, } \\
\text { Morphometric } \\
\text { measurement, } \\
\text { Sesamum indicum }\end{array}$ \\
Article Info \\
$\begin{array}{l}\text { Accepted: } \\
\text { 22 June } 2020 \\
\text { Available Online: } \\
\text { 20 July } 2020\end{array}$ \\
\hline
\end{tabular}

\section{Introduction}

Oilseed crops are one of the most important determinants of agricultural economy next to cereals. Oilseeds serve as a basis for biological systems by producing edible oils that contribute to the dietary lipid requirement of human beings. Sesamum indicum L. (Pedaliaceae) is an ancient oilseed crop, grown throughout the tropical and subtropical region of the world and regarded as "queen of oilseeds". India ranks 5 th in total production
Studies on the biology of Corcyra cephalonica on three sesamum (Sesamum indicum) varieties viz. Smarak (white), Amrit (brown) and Prachi (black) were carried out. The mean duration of egg, larval, pupal and adult period of Corcyra cephalonica were recorded 3.67, 27.73, 7.80 and 6.80 days on variety Smarak, 5.00, 28.73, 8.73 and 7.60 days on variety Amrit and 5.80, 30.13, 10.40 and 8.40 days on variety Prachi respectively. The result of morphometric measurements revealed that the average length and breadth of egg, $1^{\text {st }}, 2^{\text {nd }}, 3^{\text {rd }}, 4^{\text {th }}, 5^{\text {th }}$ instars larva, pupa were $0.41 \mathrm{~mm}$ and $0.30 \mathrm{~mm}, 1.80 \mathrm{~mm}$ and $0.31 \mathrm{~mm}, 3.12 \mathrm{~mm}$ and $0.35 \mathrm{~mm}, 5.60 \mathrm{~mm}$ and $0.89 \mathrm{~mm}, 7.52 \mathrm{~mm}$ and $1.12 \mathrm{~mm}, 10.01 \mathrm{~mm}$ and $1.54 \mathrm{~mm}$, $8.40 \mathrm{~mm}$ and $1.80 \mathrm{~mm}$ respectively. The mean measurement across the expanded wings of male moth was $12.99 \mathrm{~mm}$ and in females was $16.38 \mathrm{~mm}$, whereas the mean body length of male was $10.72 \mathrm{~mm}$ and in female was $12.24 \mathrm{~mm}$. of sesamum in the world. In Odisha sesamum is grown over an area of about 212.85 thousand hectares and the annual production is around 0.55 lakh tonne (Annual report 2015-16, Directorate of Agriculture and Food Production, Odisha). In Odisha sesamum varieties like Nirmala, Prachi, Amrit, Subhra and Smrak are grown mainly in the districts like Angul, Dhenkanal, Ganjam, Malkangiri, Sundargarh, Sambalpur and Bolangir (Patnaik et al., 2013). 
Sesamum is attacked by many insect pests not only in field condition but also in storage. Among different major pests of stored sesamum, rice moth, Corcyra cephalonica Stain. is most important feeder that cause maximum damage up to $94 \%$ in sesamum seeds (Kumar, 2012). According to Wadaskar et al., (2016), Corcyra cephalonica has been introduced by the Rice trade. They cause a great loss to sesamum by feeding on seeds and make silken webs. In extreme case, the entire seed stock is converted into a black webbed mass that emit a characteristic foul smell. The stored seeds become unfit for human consumption. So the present work was undertaken to study different developmental stages of Corcyra cephalonica Stain. on different varieties of sesamum seeds during storage condition.

\section{Materials and Methods}

Laboratory experiments were conducted to study the biology of Corcyra cephalonica on three sesamum varieties (Smarak, Amrit and Prachi) during the year 2018-19 in the Department of Entomology, Odisha University of Agriculture and Technology (OUAT), Bhubaneswar, Odisha.

Eggs of Corcyra cephalonica were collected from the biocontrol laboratory of Department of Entomology and was masscultured by spreading $0.2 \mathrm{cc}$ eggs of rice moth in $1 \mathrm{~kg}$ of broken sesamum seeds in a plastic jar $(25 \mathrm{~cm}$ long x $10 \mathrm{~cm}$ diameter). Three cultures were prepared on three sesamum varieties (Smarak, Amrit and Prachi). All jars were covered with muslin cloth and tied with rubber band. Regular observation of moth emergence was done periodically. Adults obtained from the culture were released in egg laying apparatus, that was made with a plastic funnel $(18 \mathrm{~cm}$ long $\mathrm{x} 13 \mathrm{~cm}$ diameter), with the lower side was fitted with a wire gauge (60 mm mesh) and eggs were collected beneath on a glass plate on which the apparatus was placed. Collected eggs were further released into jars containing sesamum seeds and a series of culture also maintained to obtain sufficient adults for further investigation.

Life cycle study was conducted under laboratory conditions on three varieties of sesamum seeds viz. Smarak, Amrit and Prachi during Sept and October 2018, when the laboratory temperature and relative humidity were in the range of $25.2^{\circ} \mathrm{C}$ to $32.6^{\circ} \mathrm{C}$ and 74 to 94 per cent $\mathrm{RH}$ and $22.8^{\circ} \mathrm{C}$ to $32.5^{\circ} \mathrm{C}$ and 60 to 94 per cent $\mathrm{RH}$, respectively.

Cleaned sesamum seeds $(30 \mathrm{~g})$ were taken in thirty cleaned plastic boxes $(9 \mathrm{~cm}$ long $X 8 \mathrm{~cm}$ diameter) and freshly emerged adults, one pair each of male and female were collected from the stock culture and were enclosed in separate boxes. After oviposition eggs were collected in different petri dishes and duration of egg period was recorded. From petri dishes, freshly hatched first instar larva one per each boxes containing sesamum seeds was introduced by using a fine camel hair brush. The boxes were covered with muslin cloth and tied with rubber band. Same procedure was repeated for all varieties. Out of 30 observation samples, 15 were taken for to study the duration of different larval instars, pupal period and adult longevity of Corcyra cephalonica Stain. was carried out. biology study.

Study on fecundity and adult longevity of adult Corcyra cephalonica Stain. was made with and without food where fifteen plastic boxes $(9 \mathrm{~cm}$ long $X 8 \mathrm{~cm}$ diameter) were maintained by releasing one pair of freshly emerged adults of male and female into each box and were provided with 50 per cent honey solution as food and another set of 15 boxes were enclosed with freshly emerged adult male and female (as one pair) without supply of any food. The boxes were covered 
with muslin clothes and tied with rubber bands. Observations were taken on fecundity, duration of pre-oviposition period, oviposition period post-oviposition period and adult longevity.

\section{Results and Discussion}

\section{Egg stage}

Freshly laid eggs were glistening pearly white in colour and possessed a minute protuberance at one end (Figure 1). Similar observations were made by Shailaja (2008). It was found that the duration of egg period ranged from 2 to 5 days with an average of $3.67 \pm 0.90$ days on Smarak, 4 to 6 days with an average of $5.00 \pm 0.85$ days on Amrit and 5 to 6 days with an average of $5.80 \pm 0.41$ days on Prachi variety of sesamum (Table 1). The length and breadth of egg of rice moth measured were $0.41 \mathrm{~mm}$ and $0.30 \mathrm{~mm}$ respectively (Table 2). Similar results were also reported by Menge and Naik (2017) and Jagannath (2009).

\section{First instar larva}

The first instar larvae emerged by biting through the chorion were very minute dirty white in colour and possessed pale yellowish colour head capsule (Figure 2). The larval duration recorded were from 4 to 5 days with an average of $4.40 \pm 0.51$ days on variety Smarak, 3 to 5 days with an average of $3.73 \pm$ 0.80 days on variety Amrit and 4 to 6 days with an average of $5.00 \pm 0.93$ days on variety Prachi (Table 1). The length and breadth of first instar larva measured were $1.80 \mathrm{~mm}$ and $0.31 \mathrm{~mm}$ respectively (Table 2). Similar results were also reported by Sailaja (2008).

\section{Second instar larva}

The second instar larva can be distinguished from previous instar by the deep yellowish brown colour head capsule and a more pronounced thoracic shield. Larva was dirty white in colour (Figure 3 ). The larval duration ranged from 6 to 7 days with a mean of $6.27 \pm$ 0.46 days on variety Smarak, 5 to 6 days with a mean of $5.47 \pm 0.52$ days on variety Amrit and 5 to 6 days with a mean of $5.40 \pm 0.51$ days on variety Prachi (Table 1). The larva measured $3.12 \mathrm{~mm}$ body length with a breadth of $0.35 \mathrm{~mm}$ (Table 2). This findings are closely related with the findings of Sailaja (2008).

\section{Third instar larva}

The third instar larvae differed markedly from preceding two stages by having a dark brown head capsule with more distinct thoracic shield and anal plate. They fed under dense silken cylindrical covering secreted by them (Figure 4). The larval duration ranged from 5 to 6 days with an average of $5.40 \pm 0.51$ days on variety Smarak, 5 to 6 days with an average of $5.60 \pm 0.51$ days on variety Amrit and 4 to 6 days with an average of $4.93 \pm 0.96$ days on variety Prachi (Table 1). The mean body length and breadth of larva was measured $5.60 \mathrm{~mm}$ and $0.89 \mathrm{~mm}$ respectively (Table 2). Same findings were also reported by Sailaja (2008).

\section{Fourth instar larva}

The fourth instar larva were dirty white in colour with a dark border line and found under thick silken gallery which was adhered with numerous pellets of excreta, frass and seeds (Figure 5). The larva also possessed a wavy dirty streak along the dorsal line on the abdomen. The larva was found less active and seeks hiding places when exposed to light. The larval duration ranged from 5 to 6 days with a mean of $5.60 \pm 0.51$ days on variety Smarak, 5 to 7 days with a mean of $6.27 \pm$ 0.88 days on variety Amrit and 6 to 7 days with a mean of $6.40 \pm 0.51$ days on variety 
Prachi (Table 1). The mean body length and breadth of the larva measured $7.52 \mathrm{~mm}$ and $1.12 \mathrm{~mm}$ respectively (Table 2). This information is in close conformity with the observations taken by Sailaja (2008).

\section{Fifth instar larva}

The fifth instar larva was dirty white in colour and more or less cylindrical in shape. The head capsule was reddish brown with a distinct yellowish brown thoracic shield and dusky brown anal plate (Figure 6). Observed larval duration was 7 to 8 days with a mean of $7.33 \pm 0.49$ days on variety Smarak, 8 to 9 days with a mean of $8.33 \pm 0.49$ days on variety Amrit and 9 to 10 days with a mean of $9.33 \pm 0.49$ days on variety Prachi (Table 1). The mean larva body length and breadth measured were $10.01 \mathrm{~mm}$ and $1.54 \mathrm{~mm}$ respectively (Table 2). Similar results were also reported by Sailaja (2008).

\section{Pupal stage}

The leathery brown coloured pupa was enclosed in a cocoon, which was more or less elongate and somewhat elliptical at one end (Figure 8). The white silken cocoon was thinly woven and covered with seeds of sesamum, debris and excrement (Figure 7). The pupal duration ranged 7 to 9 days with a mean of $7.80 \pm 0.68$ days on Smarak, 7 to 10 days with a mean of $8.73 \pm 0.96$ days on Amrit and 9 to 12 days with a mean of $10.40 \pm 0.99$ days on Prachi variety (Table 1). The mean length and breadth of pupa measured were $8.40 \mathrm{~mm}$ and $1.80 \mathrm{~mm}$ respectively (Table 2 ). This information is in close conformity with the observations taken by Menge et al., (2018).

\section{Adult stage}

The adults moths were dark greyish-brown in colour with a few dark hair lines. The females were generally larger than males. The head was elongate with snout like projection of labial palpi in females whereas projection was less conspicuous and blunted in males (Figure $9)$. Adult longevity of moth was ranged from 6 to 8 days with a mean of $6.80 \pm 0.77$ days on Smarak, 7 to 9 days with a mean of $7.60 \pm$ 0.74 days on Amrit and 6 to 12 days with a mean of $8.40 \pm 2.20$ days on variety Prachi (Table 1). The mean measurement across the expanded wings of male moth was $12.99 \mathrm{~mm}$ and that of the females was $16.38 \mathrm{~mm}$, whereas the mean body length of male was $10.72 \mathrm{~mm}$ and in female was $12.24 \mathrm{~mm}$ (Table 2). This information closely corroborates the findings of Kumar et al., (2018), Menge and Naik (2017) and Sailaja (2008), who reported similar period of adult longevity of $C$. cephalonica.

\section{Duration of total life period of Corcyra cephalonica Stain. on stored sesamum varieties}

Among the varieties tested the mean duration of egg period of Corcyra cephalonica was 3.67days, 5.00 days and 5.80 days on variety Smarak, Amrit and Prachi respectively. In case of the egg period was. The mean larval period varied from 27.73 days on Smarak to 30.13 days on Prachi and on Amrit it was 28.73 days. The pupal and adult periods varied from 7.80 and 6.80days on Smarak to 10.40 and 8.40 days on Prachi respectively. The pupal and adult period on variety Amrit was intermediate between Smarak and Prachi was 8.73 and 7.60 days respectively.

The total life period of rice moth varied from 46.00 days on white seeded variety Smarak to 54.73 days on black seeded variety Prachi, whereas 50.06 days on brown seeded variety Amrit (Table 3). These findings on larval instars is in conformity with the observation taken by Majhi (2000) and Kumar (2012). 
Table.1 Duration of different life stages of Corcyra cephalonica Stain. on variety Smarak, Amrit and Prachi

\begin{tabular}{|c|c|c|c|c|c|c|}
\hline \multirow[t]{3}{*}{ Stages of insect } & \multicolumn{6}{|c|}{ Sesamum cultivars } \\
\hline & \multicolumn{2}{|c|}{ Smarak } & \multicolumn{2}{|c|}{ Amrit } & \multicolumn{2}{|c|}{ Prachi } \\
\hline & $\begin{array}{l}\text { Range } \\
\text { (days) }\end{array}$ & $\begin{array}{c}\text { Mean } \pm \text { SD }^{*} \\
\quad(\text { days })\end{array}$ & $\begin{array}{l}\text { Range } \\
\text { (days) }\end{array}$ & $\begin{array}{c}\text { Mean } \pm \text { SD* } \\
\text { (days) }\end{array}$ & $\begin{array}{l}\text { Range } \\
\text { (days) }\end{array}$ & $\underset{\text { (days) }}{\operatorname{Mean} \pm \text { SD* }}$ \\
\hline Egg & $2-5$ & $3.67 \pm 0.90$ & $4-6$ & $5.00 \pm 0.85$ & $5-6$ & $5.80 \pm 0.41$ \\
\hline \multicolumn{7}{|l|}{ Larval instars } \\
\hline $1^{\text {st }}$ instar & $4-5$ & $4.40 \pm 0.51$ & $3-5$ & $3.73 \pm 0.80$ & $4-6$ & $5.00 \pm 0.93$ \\
\hline $2^{\text {nd }}$ instar & 6-7 & $6.27 \pm 0.46$ & $5-6$ & $5.47 \pm 0.52$ & $5-6$ & $5.40 \pm 0.51$ \\
\hline $3^{\text {rd }}$ instar & $5-6$ & $5.40 \pm 0.51$ & $5-6$ & $5.60 \pm 0.51$ & $4-6$ & $4.93 \pm 0.96$ \\
\hline $4^{\text {th }}$ instar & $5-6$ & $5.60 \pm 0.51$ & $5-7$ & $6.27 \pm 0.88$ & 6-7 & $6.40 \pm 0.51$ \\
\hline $5^{\text {th }}$ instar & $7-8$ & $7.33 \pm 0.49$ & $8-9$ & $8.33 \pm 0.49$ & $9-10$ & $9.33 \pm 0.49$ \\
\hline Total larval period & $27-32$ & $27.73 \pm 1.98$ & $26-33$ & $28.73 \pm 2.22$ & $28-35$ & $30.13 \pm 2.39$ \\
\hline Pupal period & $7-9$ & $7.80 \pm 0.68$ & $7-10$ & $8.73 \pm 0.96$ & $9-12$ & $10.40 \pm 0.99$ \\
\hline Adult period & $6-8$ & $6.80 \pm 0.77$ & $7-9$ & $7.60 \pm 0.74$ & $6-12$ & $8.40 \pm 2.20$ \\
\hline
\end{tabular}

*Mean of 15 replications

Table.2 Morphological measurement of different stages of rice moth Corcyra cephalonica Stain on variety Smarak

\begin{tabular}{|l|c|c|}
\hline \multicolumn{1}{|c|}{ Stages } & Length $(\mathbf{m m})^{*}$ & Breadth/ wingspan $(\mathbf{m m})^{*}$ \\
\hline Egg & 0.41 & 0.30 \\
\hline $\mathbf{1}^{\text {st }}$ instar & 1.80 & 0.31 \\
\hline $\mathbf{2}^{\text {nd }}$ instar & 3.12 & 0.35 \\
\hline $\mathbf{3}^{\text {rd }}$ instar & 5.60 & 0.89 \\
\hline $\mathbf{4}^{\text {th }}$ instar & 7.52 & 1.12 \\
\hline $\mathbf{5}^{\text {th }}$ instar & 10.01 & 1.54 \\
\hline Pupa & 8.40 & 1.80 \\
\hline Adult male & 10.72 & 12.99 \\
\hline Adult female & 12.24 & 16.38 \\
\hline
\end{tabular}

*Mean of 10 replication

Table.3 Difference in the duration of life stages of Corcyra cephalonica Stain on sesamum cultivars

\begin{tabular}{|l|c|c|c|c|c|}
\hline \multicolumn{1}{|c|}{ Varieties } & Egg period* & $\begin{array}{c}\text { Larval } \\
\text { period* }\end{array}$ & $\begin{array}{c}\text { Pupal } \\
\text { period* }\end{array}$ & $\begin{array}{c}\text { Adult } \\
\text { period* }\end{array}$ & $\begin{array}{c}\text { Total life } \\
\text { cycle }\end{array}$ \\
\hline Smarak & 3.67 & 27.73 & 7.80 & 6.80 & 46.00 \\
\hline Amrit & 5.00 & 28.73 & 8.73 & 7.60 & 50.06 \\
\hline Prachi & 5.80 & 30.13 & 10.40 & 8.40 & 54.73 \\
\hline S.E.m( $\mathbf{\pm})$ & 0.194 & 0.568 & 0.229 & 0.364 & \\
\hline C.D.(0.05) & 0.554 & 1.622 & 0.653 & 1.040 & \\
\hline
\end{tabular}

*Mean of 15 replications 
Table.4 Effect on fecundity and adult longevity in Corcyra cephalonica Stain with and without food

\begin{tabular}{|l|c|c|c|c|}
\hline \multirow{2}{*}{ Adult period and fecundity } & \multicolumn{2}{|c|}{ Without food } & \multicolumn{2}{c|}{ With food ( 50\% honey solution) } \\
\cline { 2 - 5 } & Range & Mean \pm SD $*$ & Range & Mean \pm SD* \\
\hline Pre-oviposition period (days) & $1-2$ & $1.33 \pm 0.49$ & $1-2$ & $1.60 \pm 0.51$ \\
\hline Oviposition period (days) & $2-3$ & $2.33 \pm 0.49$ & $2-4$ & $3.13 \pm 0.83$ \\
\hline Post-oviposition period (days) & $1-3$ & $2.53 \pm 0.52$ & $4-5$ & $4.33 \pm 0.49$ \\
\hline Fecundity (in No.) & $106-202$ & $149.60 \pm 27.36$ & $178-253$ & $231.47 \pm 23.21$ \\
\hline $\begin{array}{l}\text { Adult longevity(days) } \\
\text { a) Male }\end{array}$ & $3-8$ & $5.60 \pm 1.80$ & $6-10$ & $8.20 \pm 1.61$ \\
b) Female & $4-8$ & $6.07 \pm 1.39$ & $7-11$ & $8.47 \pm 0.99$ \\
\hline
\end{tabular}

*Mean of 15 replications

Fig.1 Eggs of Corcyra cephalonica Stain

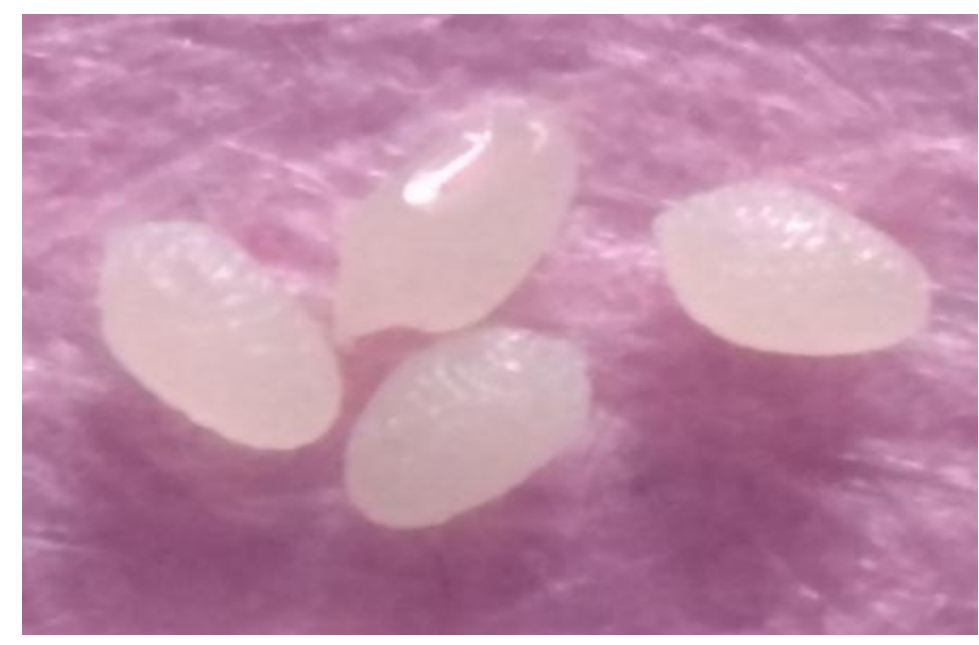

Fig.2 First instar larva of Corcyra cephalonica Stain

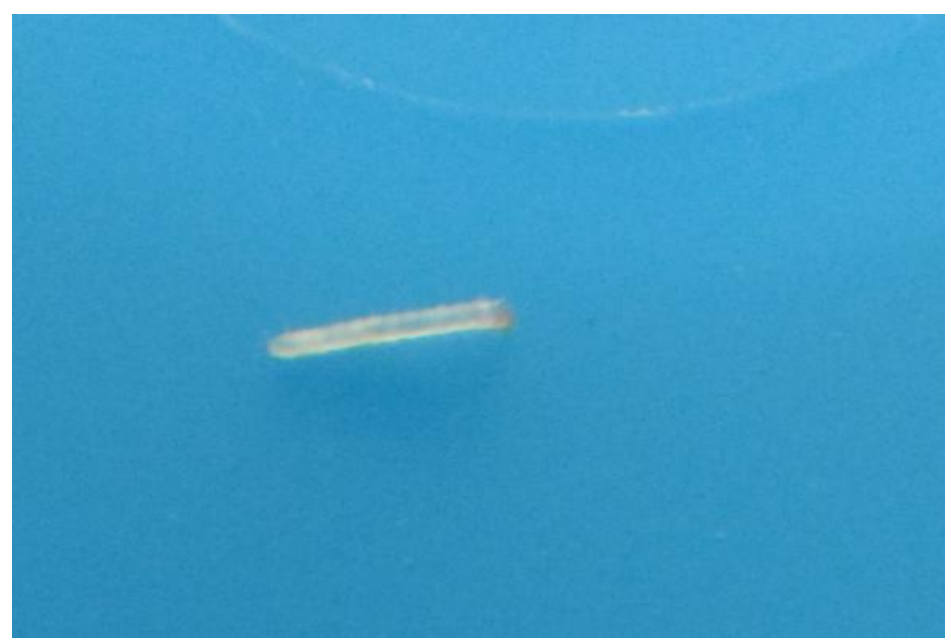


Fig.3 Second instar larva of Corcyra cephalonica Stain

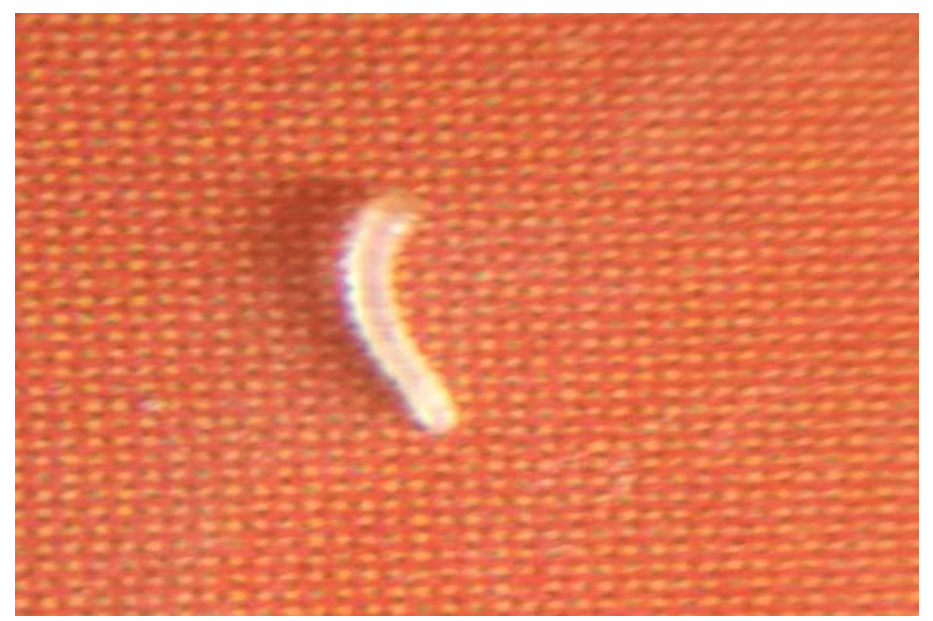

Fig.4 Third instar larva of Corcyra cephalonica Stain

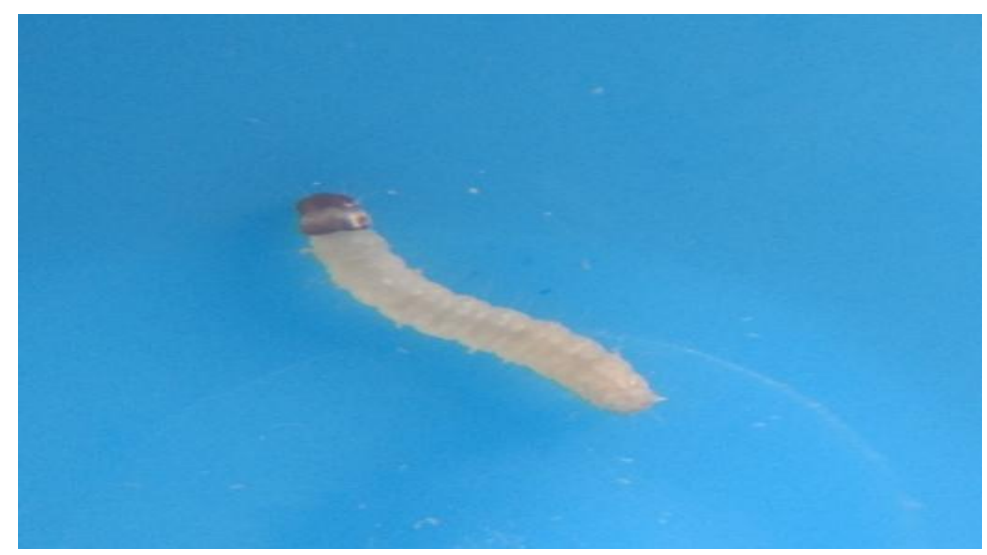

Fig.5 Fourth instar larva of Corcyra cephalonica Stain

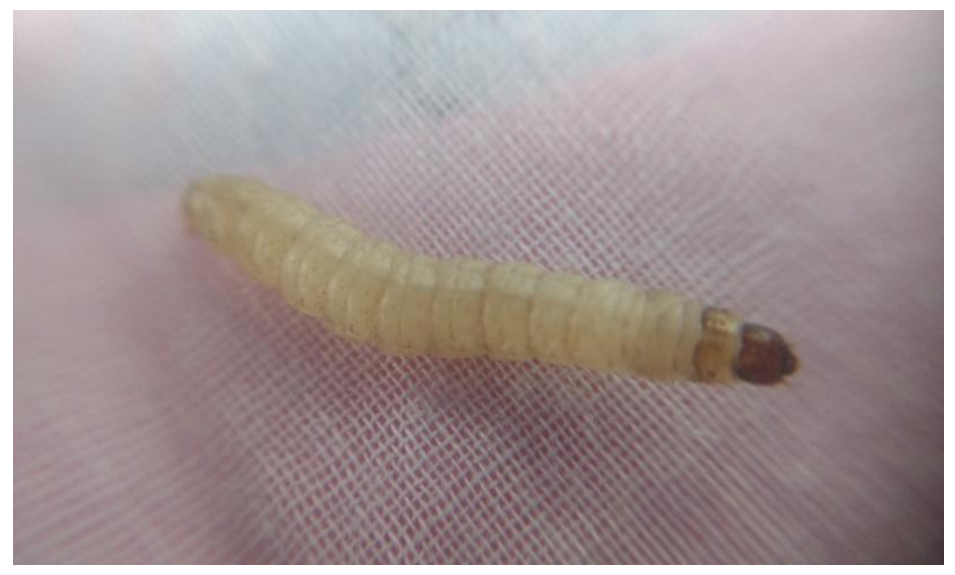


Fig.6 Fifth instar larva of Corcyra cephalonica Stain

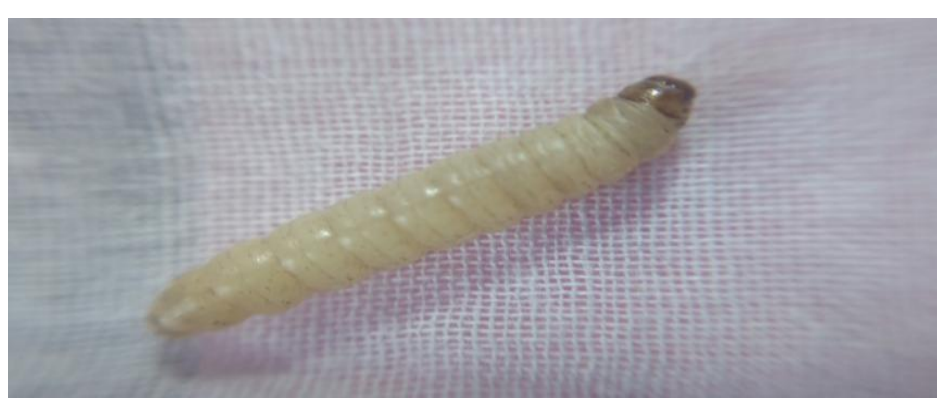

Fig.7 Cocoon of Corcyra cephalonica Stain

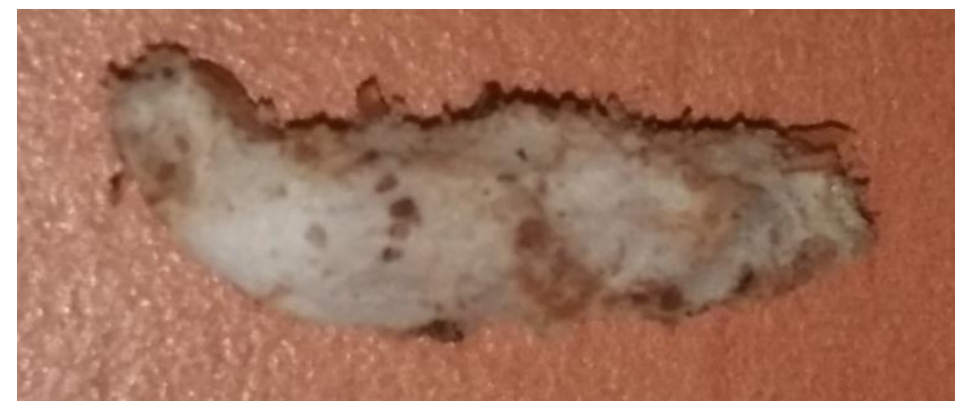

Fig.8 Pupa of Corcyra cephalonica Stain

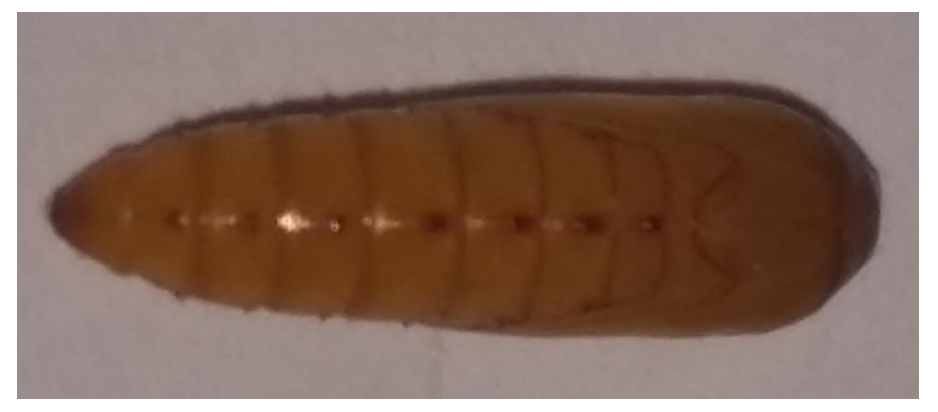

Fig.9 A. Male of Corcyra cephalonica Stain B. Female of Corcyra cephalonica Stain

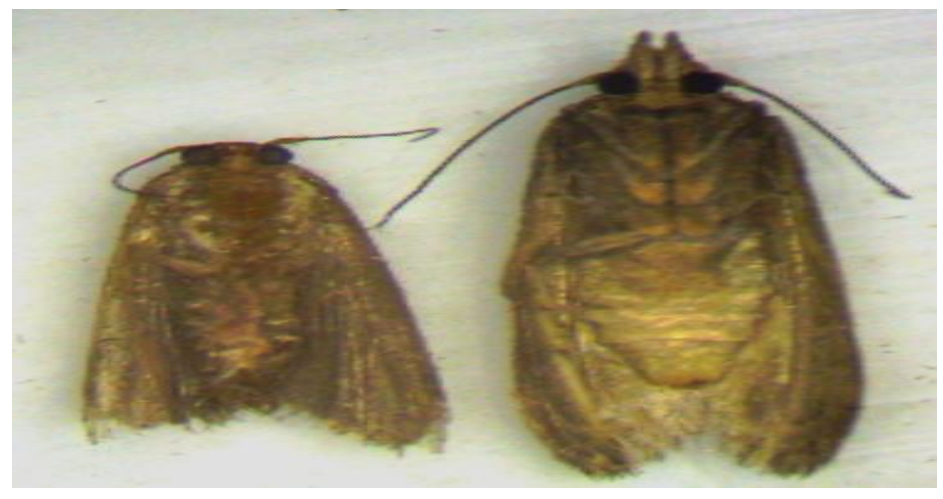


Fecundity and adult longevity of Corcyra cephalonica Stain

In the present investigation, considerable variation was found on the fecundity and adult longevity of adult rice moth provided with $50 \%$ honey solution as food and without food.

Fecundity without food was ranged from 106 to 202 with a mean of $149.60 \pm 27.36$, whereas it was 178 to 253 with a mean of $231.47 \pm 23.21$ with the supply of $50 \%$ honey solution (Table 4). The present findings were in confirmity with findings of Sailaja (2008).

The average pre-oviposition period, oviposition period and post-oviposition period were $1.33 \pm 0.49,2.33 \pm 0.49$, and $2.53 \pm 0.52$ days without food. It was $1.60 \pm 0.51,3.13 \pm$ 0.83 and $4.33 \pm 0.49$ days when provided with $50 \%$ honey solution (Table 4). This findings were supported by Jagadish et al., (2009) and Sailaja (2008).

The average adult longevity of male and female were $5.60 \pm 1.80$ and $6.07 \pm 1.39$ days without food and was $8.20 \pm 1.61$ and $8.47 \pm$ 0.99 days with provision of $50 \%$ honey solution respectively (Table 4). The present findings support the results of Kumar et al., (2018) and Menge and Naik (2017).

In conclusions under Bhubaneswar agroclimatic conditions of Odisha the rice moth Corcyra cephalonica Stain. is a major pest of stored sesamum. The insect passes through five larval instars before pupation and pupates in a concealed condition. Among the three varieties tested the mean egg, larva, pupa and adult period of Corcyra cephalonica on white seeded variety Smarak was found to be shortest whereas longest duration was on black seeded variety Prachi. Under Odisha condition the total life cycle of $C$. cephalonica is completed within 46 to 54 days on sesamum varieties.

\section{References}

Annual report 2015-16, Directorate of Agriculture and Food Production, Odisha.

Jagadish, P. S., P.Nirmala, M. A. Rashmi, J. N. Hedge and Nangia, N. 2009. Biology of rice moth, Corcyra cephalonica (Stainton) on foxtail millet Setaria italica (L.). Karnataka. Journal of Agricultural Science, 22: 674-675.

Kumar, S. 2012. Studies on insect pest infestation of mungbean and sesame seeds and it's effect on seed quality, Odisha, India. M.Sc. Thesis, Odisha University of Agriculture and Technology, Bhubaneswar, India.

Kumar, A. K. M., V. J. Tambe, S. K. Rehaman, B. N. Choudhuri and Thakur, K. D.2018. Effect of different diets on the biology of rice moth, Corcyra cephalonica (Stainton), Journal of Entomology and Zoology Studies, 6(3): 251-254.

Majhi, B. K. 2000. Management of major insect pests of stored sesamum, Odisha, India. M.Sc. Thesis, Odisha University of Agriculture and Technology, Bhubaneswar, India.

Menge, A. K. and Naik, K. V. 2017. Biology of Rice Moth Corcyra cephalonica (Stainton) on Groundnut Variety Konkan Gaurav, Advanced Agricultural Research \& Technology Journal, 1(2).

Menge, A. K., K. V. Naik and Golvankar, G. M..2018. Evaluate of plant products against Corcyra cephalonica (St.) in stored groundnut kernel, International Journal of Chemical Studies, 6(5): 2936-2941.

Patnaik, H. P., T.Samal, M.Dash and Ranasingh, N.2013. Susceptibility of sesame varieties to rice moth and red flour beetle under storage conditions, Journal of Plant Protection and Environment, 10(2): 81-82. 
Shailaja, S., P. S. Jagadish, C. T. A. Kumar, N.Nangia, J. Gowda and Nagaraja, A. 2008. Infestation behavior and nature of damage by rice meal moth Corcyra cephalonica Stainton (Lepidoptera: Pyralidae) on proso millet ( Panicum miliaceum L.). Journal of Environment and Ecology, 27(2): 952-955.
S.Vigneswaran and Rode, N. S. 2016. Studies on effect of temperature and relative Humidity on biology of rice moth corcyra cephalonica (stainton) under laboratory condition, International of Environmental Sciences, 10(1\&2): 393-396.

Wadaskar, P. S., D. M. Jethva,

\section{How to cite this article:}

Soumya B. Babu, T. Samal, M. K. Mishra, S. Mohanty, Jubuli Sahu. 2020. Biology and Morphometry of Corcyra cephalonica Stain in Sesamum Seeds during Storage. Int.J.Curr.Microbiol.App.Sci. 9(07): 2766-2775. doi: https://doi.org/10.20546/ijcmas.2020.907.326 